\title{
EUS-FNA versus ERCP for tissue diagnosis of suspect malignant biliary strictures: a prospective comparative study
}

\section{다(1) $(\odot)$}

\section{Authors}

Diogo Turiani Hourneaux Moura, Eduardo Guidamarães Hourneaux de Moura, Sergio Eiji Matuguma, Marcos Eduardo dos Santos, Eduardo Turiani Hourneaux Moura, Felipe lankelevich Baracat, Everson LA Artifon, Spencer Cheng, Wanderley Marque Bernardo, Danielle Chacon, Ryan Tanigawa, José Jukemura

\section{Institution}

Hospital das Clínicas da Faculdade de Medicina da Universidade de São Paulo - Gastrointestinal Endoscopy Unit, São Paulo, Brazil

submitted 23.7.2017

accepted after revision $\quad 27.10 .2017$

\section{Bibliography}

DOI https://doi.org/10.1055/s-0043-123186 |

Endoscopy International Open 2018; 06: E769-E777

(c) Georg Thieme Verlag KG Stuttgart · New York ISSN 2364-3722

\section{Corresponding author}

Diogo Turiani Hourneaux Moura, Hospital das Clínicas da Faculdade de Medicina da Universidade de São Paulo Gastrointestinal Endoscopy Unit, Rua Ana Vieira de Carvalho, 362, casa 15 São Paulo, São Paulo 05679065, Brazil

Fax: +55-113-885-7981

dthmoura@hotmail.com

\section{ABSTRACT}

Background and study aims Biliary strictures are frequently a challenging clinical scenario and the anatomopathological diagnosis is essential in the therapeutic management, whether for curative or palliative purposes. The acquisition of specimens is necessary since many benign diseases mimic biliopancreatic neoplasms. Endscopic retrograde cholangiopancreatography (ERCP) is the traditionally used method despite the low sensitivity of biliary brush cytology and forceps biopsy. On the other hand, several studies reported good accuracy rates using endoscopic ultrasound-guided fine-needle aspiration (EUS-FNA). The aim of this prospective study was to compare, the accuracy of EUSFNA and ERCP for tissue sampling of biliary strictures.
Patients and methods After performing the sample size calculation, 50 consecutive patients with indeterminate biliary strictures were included to undergo ERCP and EUS on the same sedation.The gold-standard was surgery or 6 months' follow-up. Evaluation of the diagnostic indices (sensitivity, specificity, positive and negative predictive value, positive and negative likelihood ratio), concordance and adverse events among the methods were performed. Also, subtype analyses of the techniques, anatomical localization and size of the lesion were included.

Results The final diagnoses reported in 50 patients were 47 malignant, 1 suspicious and 2 benign lesions. 31 lesions were extraductal and 19 intraductal, 35 were distal and 15 proximal strictures. In the intention-to-treat analysis, the sensitivity and accuracy of EUS-FNA were superior than ERCP tissue sampling (93,8\%, $94 \%$ vs. 60,4\%, $62 \%$, respectively) $(P=0.034)$, with similar adverse events. There was no concordance between the methods and combining both methods improved the sensitivity and accuracy for $97.9 \%$ and $98 \%$, respectively. In the subtype analyses, the EUSFNA was superior, with a higher accuracy than ERCP tissue sampling in evaluating extraductal lesions (100\% vs. $54.8 \%, P=0.019)$ and in those larger than $1.5 \mathrm{~cm}(95.8 \%$ vs. $61.9 \%, P=0.031$ ), but were similar in evaluating intraductal lesions and lesions smaller than $1.5 \mathrm{~cm}$. There was no significant difference between the methods in the analyzes of proximal, distal and pancreatic lesions.

Conclusion EUS-FNA is better than ERCP with brush cytology and intraductal forceps biopsy in diagnosing malignant biliary strictures, mainly in the assessment of extraductal lesions and in those larger than $1.5 \mathrm{~cm}$. Combining ERCP with tissue sampling and EUS-FNA is feasible, the techniques have similar complication rates, and the combination greatly improves diagnostic accuracy. 


\section{Introduction}

Biliary strictures are frequently a challenging clinical scenario, both in their diagnosis and in their therapy, either for curative or palliative purposes. The clinical history, physical examination, complementary test and anatomopathological studies are fundamental to differentiate benign or malignant biliary strictures [1,2].

The most common causes of benign biliary strictures are postoperative, inflammatory and pancreatic, all with similar clinical features to malignant biliary strictures. Cholangiocarcinoma, tumors that invade or compress the biliary tract (pancreatic and gallbladder cancers and hepatocellular carcinoma), and lymph node metastases are among the malignant most common causes [3].

Among the different minimally invasive procedures, endoscopic retrograde cholangiopancreatography (ERCP) and endoscopic ultrasound (EUS) are essential for the diagnosis of biliary strictures of indeterminate origin. Both allowing the visualization of the strictures height, characteristics to determinate the possible causes of the stricture and obtaining tissue sampling [4-6].

In addition to traditional methods, image enhancement technologies such as cholangioscopy, optical coherence tomography and intraductal ultrasound are also available. Diagnostic tools involving cellular analysis, such as confocal endomicroscopy, and methods analyzing biological and molecular markers, such as fluorescence in situ hybridization are still emerging. Among the methods that involve advances in the diagnostic imaging with EUS, the elastography and contrast enhanced image are available [7,8].

Despite the various innovations, those listed above do not present the possibility of cellular or tissue sampling and as is oft quoted and remains true, "tissue is the issue." Ideally, any tissue sampling technique should have high sensitivity for detecting malignancy while maintaining absolute specificity, and as with any procedure, should be safe, simple, and relatively inexpensive so they can be widely used. [9].

There are several techniques for tissue acquisition. Traditionally, patients with indeterminate biliary strictures are treated with ERCP. But due to the low sensitivity of biliary brush cytology (ERCP-BB) and forceps biopsy (ERCP-FB), the use EUSguided fine-needle aspiration (EUS-FNA) has been rising in popularity [10-12]. In the literature, there are scant data that compare the 2 modalities in terms of tissue sampling. In this study, we directly compare the diagnostic yield of same-session ERCP with tissue sampling and EUS-FNA in a prospective series of patients with suspected malignant biliary obstruction.

The aim of this research was to compare results of anatomopathological diagnosis of EUS-FNA and ERCP-based biliary brush cytology and forceps biopsy in suspect malignant biliary strictures, through a comparative prospective study, evaluating the diagnostic indices (sensitivity, specificity, positive predictive value, negative predictive value, positive likelihood ratio, negative likelihood ratio and accuracy) correlated to resection specimen analysis and patient follow-up (based on patient clinical evaluation and image studies) for at least 6 months.
The secondary outcomes were evaluating level of concordance and complications between these methods (EUS and ERCP). In addition, we also performed sub-analyses to evaluate the techniques, anatomical location of the lesions (proximal versus distal and extraductal versus intraductal), their size $(<1.5 \mathrm{~cm}$ and $\geq 1.5 \mathrm{~cm})$ and each of the pancreatic lesions individually.

\section{Patients and methods}

\section{Ethical concerns}

IRB approval was granted by the ethics committee at Hospital das Clínicas - Faculty of Medicine of the University of São Paulo (CAPPesq, HCFMUSP). Written informed consent was obtained from all patients before the procedures.

\section{Patient selection}

A total of 61 consecutive patients were enrolled in this prospective study conducted from March 2016 to August 2016. Patients older than 18 years old, with suspected malignant biliary strictures based on clinical history, physical examination and imaging studies, and who signed the informed consent were included. Patients with a previous diagnosis and with a tumor arising in the main duodenal papilla or invading into the duodenum were excluded because endoscopic forceps biopsies will yield to a diagnosis.

\section{Procedures: Technical description}

All patients underwent EUS-FNA, followed by ERCP-BB and ERCP-FB during the same sedation.

During EUS-FNA, as soon as the strictures were localized, 4 passes with a 22-gauge needle were realized. We performed 2 punctures with a $10-\mathrm{mL}$ vacuum pressure syringe technique and 2 punctures with a stylet slow pull technique. The needle was moved back and forth in the lesion about 20 times in each puncture. No pathologist nor a cytopathologist was present onsite at our institution.

With the ERCP technique, 2 ERCP-BBs and ERCP-FBs were performed until at least 3 representative tissue fragments were obtained.

\section{Pathological evaluation}

Cythological evaluation

The samples obtained through EUS-FNA were transferred to 6 slides. Each smear was made with slight pressure to avoid crushing artifacts with 3 slides being placed immediately in the $96 \%$ ethyl alcohol solution and the others were fixed in the air. The remainder of the material was placed in formalin solution for the preparation of the cell-block. The samples obtained through ERCP-BB were transferred to a glass slide by slowly rotating the cytobrush bristles. 2 slides were immediately fixed, submerged in $96 \%$ ethyl alcohol solution and 1 slide was kept for air-dried staining. The tip of the brush was submerged in the formalin solution to later be made a cell-block. The whole material was sent to the Division of Anatomic Pathology, for subsequent processing and staining by Papanicolaou method 
(slides in alcohol solution), Diff-Quick Staining Protocol (airdried slides) and haematoxylin and eosin stain (cell-blocks). After this process, the cytological material was examined under the light microscope by an experienced cytopathologist.

\section{Histological evaluation}

Biopsy samples were fixed in buffered formalin, embedded in paraffin and 4- $\mu \mathrm{m}$ sections were obtained and slides were stained with hematoxylin-eosin.

The analyzes were performed by 2 pathologists experienced in the biliopancreatic pathway, based on the World Health Organization (WHO) Classification criteria [13].

The anatomopathological results of the specimens were divided into negative, suspected for malignancy, positive and inconclusive. The results were considered negative when samples lacked presence of malignant, suspicious or atypical cells, were suspect for malignancy when samples contained suspicious or atypical cells, positive when the samples contained malignant cells, and inconclusive when the cell sample was insufficient for analysis.

Immunohistochemical stains were applied to further characterize neoplastic and non-neoplastic lesions when necessary.

\section{Gold standard method}

The anatomopathological study after surgery was the gold standard method. However, because not all patients were operated due to advanced disease, patient follow-up for 6 months was also considered as a gold standard.

\section{Statistical analysis}

The sample calculation was performed using the online software power calculator for binary outcome superiority trial [14], using a statistical significance of $5 \%$ and a statistical power of $80 \%$, based on the differences in sensitivity of the methods, which were estimated in a recent systematic review and meta-analysis done prior to this study [1].

In this investigation, the sensitivity rates for EUS-FNA and ERCP with specimens were $75 \%$ and $49 \%$, respectively. The sample size calculated by the software was of 45 patients in each group and considering that the same patient was submitted to both methods, this was considered the total sample number. We also added $10 \%$ of estimated losses, giving a total of 50 patients included in the study.

The quantitative variables were analyzed by observing the minimum and maximum values, calculating the mean, median and standard deviation. The qualitative variables were calculated by the absolute and relative frequencies.

The intention-to-treat (ITT) analysis (failure of the methods was considered benign results) and the per protocol analysis were performed (failure of the methods and inconclusive results were excluded from the analysis). Cases with suspected diagnosis of malignancy were considered both benign and malignant.

The accuracy rates (sensitivity, specificity, positive predictive value, negative predictive value, positive likelihood ratio, negative likelihood ratio and accuracy) were evaluated through the software CATMAKER [15]. Concordance between the 2
Indeterminate biliary stricture: 61

Excluded:

- Major papilla tumor: 8

- Choledocholithiasis: 2

- Previous tissue diagnosis: 1

Included patients: 50

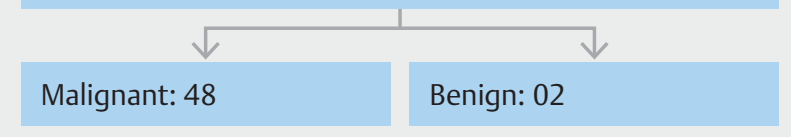

- Fig. 1 Patient selection flow diagram.

- Table 1 Anatomopathological diagnosis obtained through the combination of ERCP and EUS.

\begin{tabular}{|l|r|r|}
\hline Diagnosis & $\mathbf{n}$ & \multicolumn{1}{|c|}{$\%$} \\
\hline Adenocarcinoma & 36 & 72.0 \\
\hline IPMN & 4 & 8.0 \\
\hline Metastases & 3 & 6.0 \\
\hline Neuroendocrine tumor & 2 & 4.0 \\
\hline Adenosquamous carcinoma & 1 & 2.0 \\
\hline Positive & 1 & 2.0 \\
\hline Suspicious for malignance & 1 & 2.0 \\
\hline Fibrosis & 2 & 4.0 \\
\hline
\end{tabular}

methods was evaluated through the coefficient of agreement Kappa $(k)[16]$.

The comparison of the methods in concerning to the correct diagnosis was evaluated through the McNemar non-parametric test.

All tests were evaluated using SPSS 17.0 software, using a significance level of $5 \%$.

\section{Results}

Selection of patients with an indeterminate biliary stricture is described in > Fig. 1 .

A total of 61 patients were enrolled, 11 were excluded by the excluded criteria, the remaining 50 patients (26 female and 24 male), with a mean age of 63.08 years (range $41-86$ years) were included in the study. The mean lesion size estimated by EUS was $3.48 \mathrm{~cm}$, with a standard deviation of $1.72 \mathrm{~cm}$, and a median of $3.15 \mathrm{~cm}$ (range $0.50 \mathrm{~cm}$ to $10.80 \mathrm{~cm}$ ).

- Table1 shows results in the 50 patients with indeterminate biliary stricture by combining the 2 methods of EUS-FNA ( $\triangleright$ Fig. 2) and ERCP-based biliary brush citology ( $\triangleright$ Fig.3) and forceps biopsy (> Fig.4).

ERCP tissue sampling confirmed the diagnosis in 40 patients, in 29 of whom it was malignant and in 11 of whom it was be- 

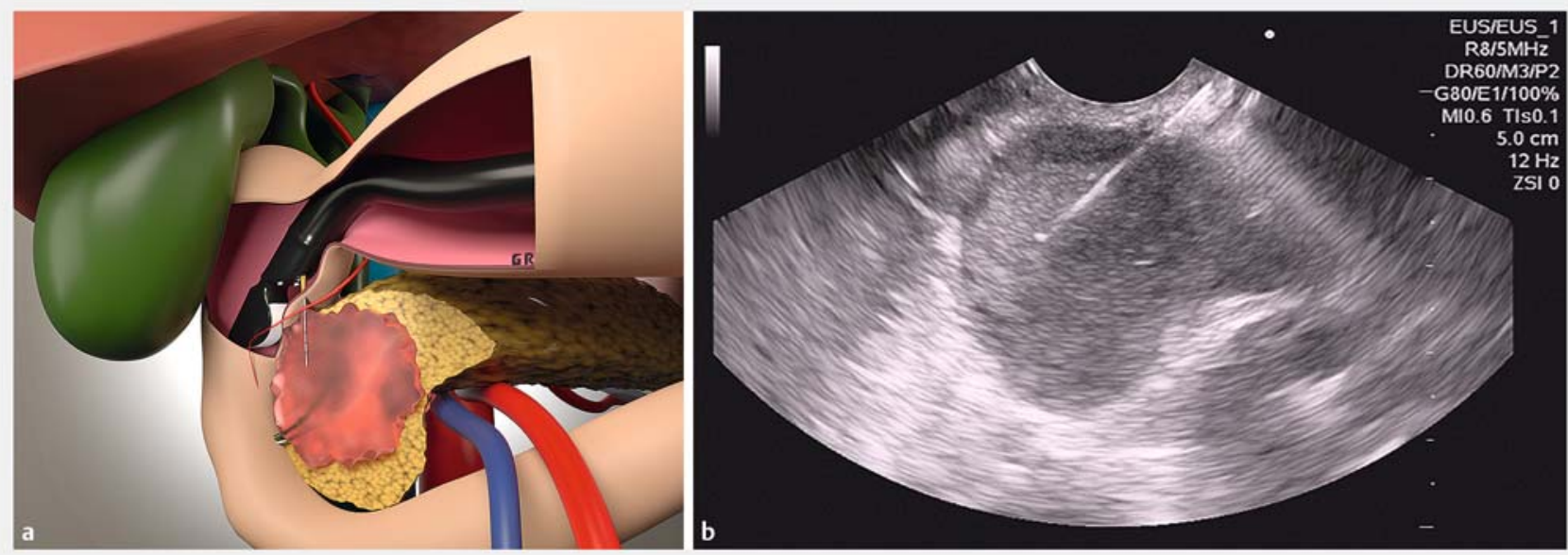

- Fig. 2 a Artistic image of EUS-FNA of a pancreatic lesion. b EUS-FNA of a pancreatic head lesion.
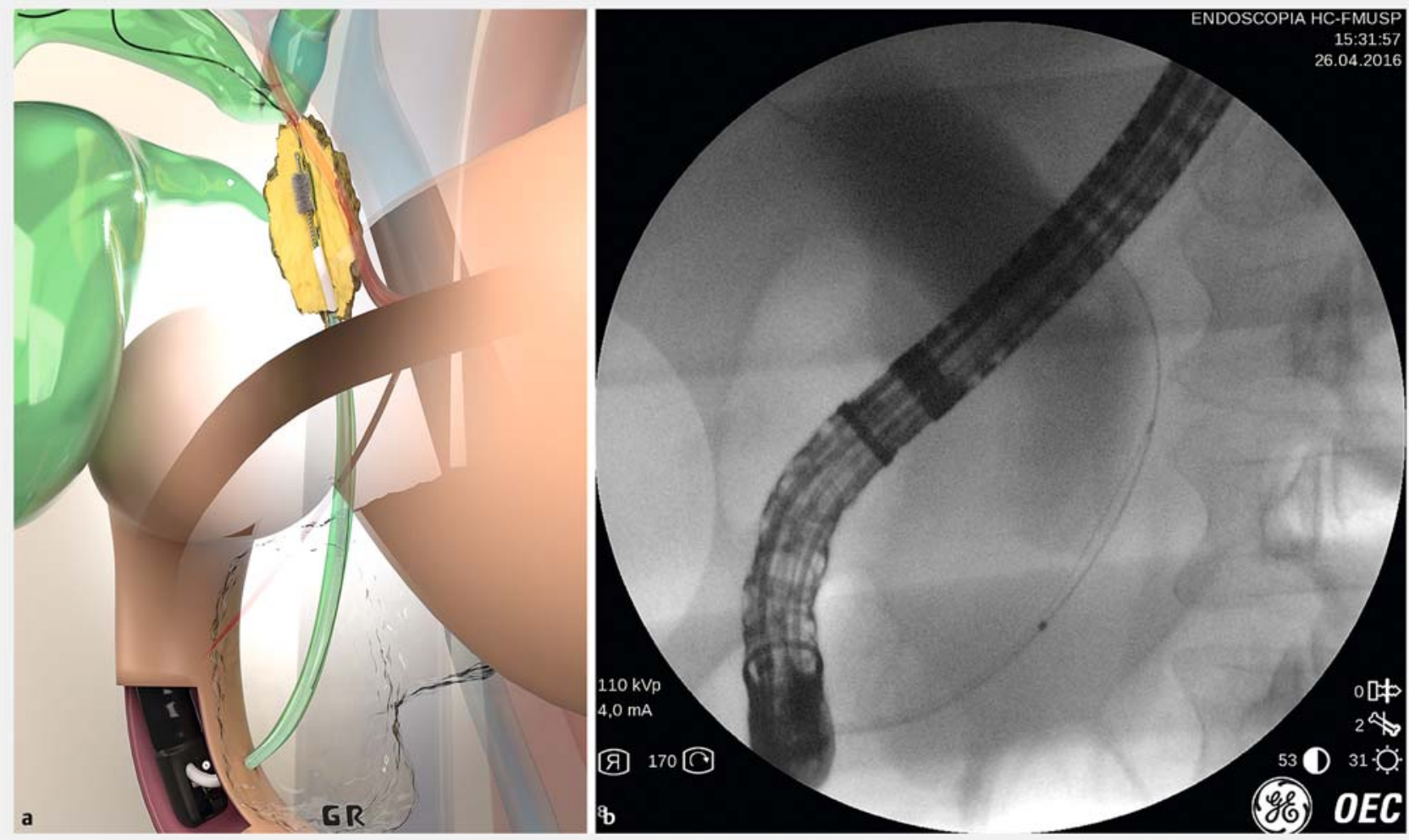

- Fig. 3 a Artistic image of ERCP biliary brush cytology. b ERCP biliary brush cytology of a distal biliary stricture.

nign. This method failed in 6 cases, 4 due to a downfall of bile duct catheterization, and 2 due to duodenal stenosis caused by the tumor. The remaining 4 patients were considered to have disease suspicious for malignancy.

EUS-FNA confirmed the diagnosis in 47 patients, in 45 of whom it was malignant and in 2 of whom it was benign. In 2 cases, the diagnosis was inconclusive due to lack of material obtained, and in 1 case it was not possible to perform the FNA due to interposition of the portal vein on the needle path.
By combining the 2 methods, tissue sampling was obtained from all patients. The anatomical location of the strictures and the final anatomopathological results of ERCP tissue sampling and EUS-FNA are visualized in $>$ Table 2.

Combining the 2 methods resulted in a malignant diagnosis in 47 cases, 2 benign lesions and 1 lesion suspicious for malignancy. Based on the gold-standard method (22 patients went to surgery and 28 for follow-up which 23 died (22 malignant and 01 suspicious), 3 are doing chemotherapy and 2 are asymp- 

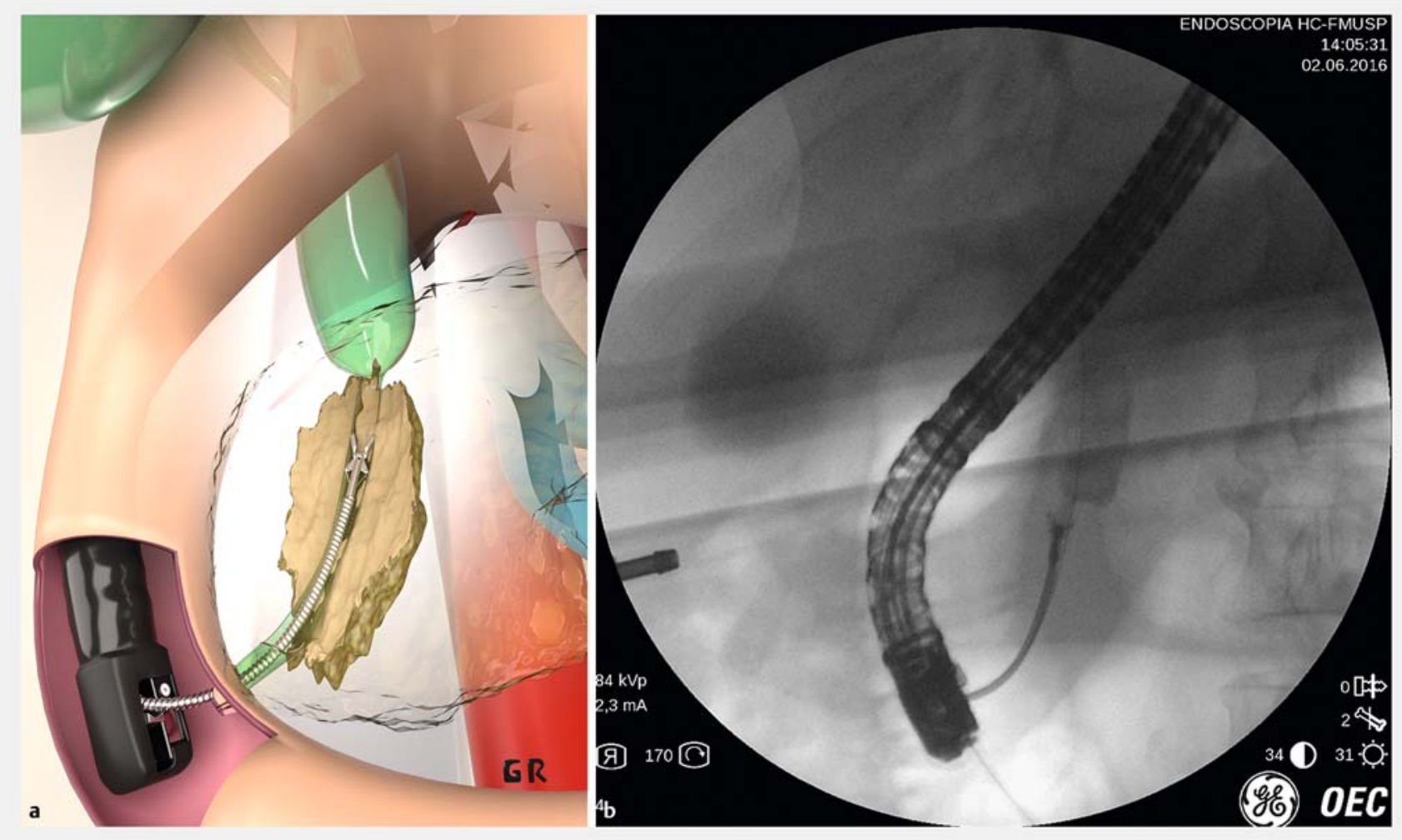

- Fig. 4 a Artistic image of ERCP forceps biopsy. b ERCP forceps biopsy of a distal biliary stricture.

- Table 2 Anatomical location and final anatomopathological results.

\begin{tabular}{|c|c|c|c|c|c|c|c|c|c|c|c|c|c|c|c|}
\hline & \multicolumn{2}{|c|}{$\begin{array}{l}\text { Proximal X } \\
\text { Distal }\end{array}$} & \multicolumn{2}{|c|}{$\begin{array}{l}\text { Intra X Extra- } \\
\text { ductal }\end{array}$} & \multicolumn{4}{|c|}{ ERCP Tissue Sampling } & \multicolumn{4}{|c|}{ EUS-FNA } & \multicolumn{2}{|c|}{$\begin{array}{l}\text { ERCP + EUS Tis- } \\
\text { sue Sampling }\end{array}$} & \multirow[b]{2}{*}{$\begin{array}{l}\text { Be- } \\
\text { nign }\end{array}$} \\
\hline & $\begin{array}{l}\text { Proxi- } \\
\text { mal }\end{array}$ & $\begin{array}{l}\text { Dis- } \\
\text { tal }\end{array}$ & $\begin{array}{l}\text { Intra } \\
\text { ductal }\end{array}$ & $\begin{array}{l}\text { Extra } \\
\text { ductal }\end{array}$ & $\begin{array}{l}\text { Malig- } \\
\text { nant }\end{array}$ & Susp. & $\begin{array}{l}\text { Be- } \\
\text { nign }\end{array}$ & Fail & $\begin{array}{l}\text { Malig- } \\
\text { nant }\end{array}$ & Inc. & $\begin{array}{l}\text { Be- } \\
\text { nign }\end{array}$ & Fail & $\begin{array}{l}\text { Malig- } \\
\text { nant }\end{array}$ & Susp. & \\
\hline $\mathrm{n}$ & 15 & 35 & 19 & 31 & 29 & 4 & 11 & 6 & 45 & 2 & 2 & 1 & 47 & 1 & 2 \\
\hline$\%$ & $30 \%$ & $70 \%$ & $38 \%$ & $62 \%$ & $58 \%$ & $8 \%$ & $22 \%$ & $12 \%$ & $90 \%$ & $4 \%$ & $4 \%$ & $2 \%$ & $94 \%$ & $2 \%$ & $4 \%$ \\
\hline
\end{tabular}

ERCP, endoscopic retrograde cholangiography; EUS-FNA, endoscopic ultrasound fine-needle aspiration; susp, suspicious; fail, failure; inc, inconclusive

tomatic without biliary stent (02 benign). The suspicious result was confirmed as malignant and all other results were confirmed as well. Therefore, 48 (96.0\%) patients were classified as having a malignant lesion and $2(4.0 \%)$ as having a benign stricture.

\section{Comparative analysis of diagnostic index of the methods}

Main analysis

Accuracy rates for the methods in the ITT analysis and considering suspicious cases as benign are shown in > Table 3.

Comparing ERCP with EUS with tissue sampling, we observed no concordance between the methods $(k=0.083, P=$ $0.195)$. When comparing accuracy, we observed that EUS was superior to ERCP in tissue sampling with statistical significance $(P=0.034)$. In the same analysis when considering suspicious cases as malignant, the sensitivity and accuracy of the EUSFNA were superior to the ERCP with tissue sampling, $93.8 \%$ and $94 \%$ versus $68.7 \%$ and $70 \%$, respectively. However, in this analysis there was no statistical significance $(P=0.095)$.

In the per protocol analysis considering suspicious cases as benign, the sensitivity and accuracy of EUS-FNA were $97.8 \%$ and $97.9 \%$ versus $69.1 \%$ and $70.6 \%$ for ERCP with tissue sampling $(P=0.068)$. In this analysis when considering suspicious cases as malignant, the sensitivity and accuracy of the EUSFNA were $97.8 \%$ and $97.9 \%$ versus $78.6 \%$ and $79.6 \%$ for ERCP with tissue sampling $(P=0,166)$. 
- Table 3 Diagnostic indices on the intention-to-treat analysis, considering suspicious results as benign.

\begin{tabular}{|l|l|l|l|l|l|l|l|}
\hline & \multicolumn{1}{|c|}{} & \multicolumn{1}{|c|}{} & & \multicolumn{2}{c|}{ Likelihood ratio } \\
\hline Brushing & S & E & PPV & NPV & A & Positive & Negative \\
\hline Forceps & $39.6 \%$ & $100 \%$ & $100 \%$ & $6.5 \%$ & $42.0 \%$ & - & 0.60 \\
\hline ERCP & $43.8 \%$ & $100 \%$ & $100 \%$ & $6.9 \%$ & $46.0 \%$ & - & 0.56 \\
\hline EUS & $60.4 \%$ & $100 \%$ & $100 \%$ & $9.5 \%$ & $62 \%$ & - & 0.40 \\
\hline ERCP+EUS & $93.8 \%$ & $100 \%$ & $100 \%$ & $40 \%$ & $94 \%$ & - & 0.06 \\
\hline
\end{tabular}

ERCP, endoscopic retrograde cholangiography; EUS, endoscopic; S, sensitivity; E, specificity; PPV, positive predictive value; NPV, negative predictive value; A, accuracy

- Table4 Intention-to-treat analysis, comparing distal and proximal strictures.

\begin{tabular}{|c|c|c|c|c|c|c|c|c|}
\hline \multirow[b]{2}{*}{ Local } & & \multirow[b]{2}{*}{$S$} & \multirow[b]{2}{*}{$\mathbf{E}$} & \multirow[b]{2}{*}{ PPV } & \multirow[b]{2}{*}{ NPV } & \multirow[b]{2}{*}{ A } & \multicolumn{2}{|c|}{ Likelihood ratio } \\
\hline & & & & & & & Positive & Negative \\
\hline \multirow[t]{3}{*}{ Distal } & ERCP & $63.6 \%$ & $100 \%$ & $100 \%$ & $14.3 \%$ & $65.7 \%$ & - & 0.36 \\
\hline & EUS & $97 \%$ & $100 \%$ & $100 \%$ & $66.7 \%$ & $97.1 \%$ & - & 0.03 \\
\hline & & & & $100 \%$ & & & & \\
\hline \multirow[t]{2}{*}{ Proximal } & ERCP & $53.3 \%$ & - & $100 \%$ & - & $53.3 \%$ & - & - \\
\hline & EUS & $86.7 \%$ & - & $100 \%$ & - & $86.7 \%$ & - & - \\
\hline
\end{tabular}

\section{Subanalysis}

We also evaluated ERCP-BB and ERCP-FB individually and observed concordance between the methods ( $k=0,251, P=$ 0.037). When comparing accuracy, we observed that ERCP-FB was superior to ERCP-BB with no statistical significance $(P=$ 0.382 ).

With ERCP and EUS tissue sampling association analysis, sensitivity was $97.9 \%$, specificity $100 \%$ and accuracy $98 \%$.

We also performed ITT analyses of the accuracy of the methods by separating the distal and proximal strictures ( $>$ Table 4) and extraductal and intraductal lesions ( $>$ Table 5), considering the suspicious cases as benign.

We did not observe significant concordance between the 2 methods, in distal $(k=0.110, P=0.162)$ or proximal strictures $(k=0.018, P=0.460)$. Despite the superiority of EUS-FNA comparing the accuracy of the techniques, we did not observe a significant difference between the methods in either distal $(P=$ $0.071)$ or proximal $(P=0.137)$ strictures.

We did not observe concordance between the methods in extraductal $(\mathrm{k}=0.000$ with $P=0.500)$ nor in intraductal strictures $(k=0.279, P=0.106)$. When comparing the accuracy of the 2 techniques, we found that EUS is superior to ERCP tissue sampling with a significant difference in evaluation of extraductal lesions $(P=0.019)$. Despite EUS superiority in detecting intraductal lesions, there was no significant difference $(P=$ $0.350)$.
It was not possible to calculate specificity in extraductal and proximal lesions, because the only 2 cases of benign lesions were intraductal and distal.

We also found it important to evaluate these strictures by separating them into 2 groups by size: bigger and smaller than $1.5 \mathrm{~cm}$ ( $\triangleright$ Table 6 ). Both approaches resulted in a $66.6 \%$ accuracy in lesions smaller than $1.5 \mathrm{~cm}$. Nonetheless, EUS was statistically significantly superior to ERCP for lesions larger than 1.5 $\mathrm{cm}$, with accuracy of $95.8 \%$ versus $61.9 \%(P=0.031)$ in the ITT analysis considering suspicious cases as benign.

In the ITT analysis of pancreatic lesions alone, EUS was $100 \%$ accurate, whereas ERCP was only $55.6 \%$ accurate $(P=0.063)$.

Only $3(6.0 \%)$ patients presented mild complications per the criteria of Freeman et al. [17]. 1 patient had hemorrhage at the apex of the papillotomy without hemodynamic repercussion and was treated endoscopically without complications. 2 presented with mild pancreatitis and were treated conservatively.

\section{Discussion}

Differentiation between benign and malignant biliary stricture is not simple, and confirmation through anatomopathological diagnosis is essential $[1,2,9]$.

Therefore, in this study we demonstrate use of ERCP and EUS in tissue diagnosis of indeterminate biliary stenosis. 
- Table 5 Intention-to-treat analysis, comparing extraductal and intraductal lesions.

\begin{tabular}{|l|l|l|l|l|l|l|l|l|}
\hline & \multicolumn{9}{|c|}{} & \multicolumn{1}{|c|}{} & \multicolumn{2}{c|}{ Likelihood ratio } \\
\hline Local & & S & E & PPV & NPV & A & Positive \\
\hline Extra- & ERCP & $54.8 \%$ & - & $100 \%$ & - & $54.8 \%$ & - \\
\hline ductal & EUS & $100 \%$ & - & $100 \%$ & - & $100 \%$ & - & - \\
\hline Intra- & ERCP & $70.6 \%$ & $100 \%$ & $100 \%$ & $28.6 \%$ & $70.6 \%$ & - & 0.33 \\
\hline ductal & EUS & $82.3 \%$ & $100 \%$ & $100 \%$ & $40 \%$ & $82.4 \%$ & - & 0.20 \\
\hline
\end{tabular}

ERCP, endoscopic retrograde cholangiography; EUS, endoscopic ultrasound; S, sensitivity; E, specificity; PPV, predictive positive value; NPV, negative predictive value; $A$, accuracy

- Table 6 Intention-to-treat analysis, comparing lesions bigger and smaller than $1.5 \mathrm{~cm}$

\begin{tabular}{|c|c|c|c|c|c|c|c|c|}
\hline \multirow[b]{2}{*}{ Local } & & \multirow[b]{2}{*}{$\mathbf{S}$} & \multirow[b]{2}{*}{$\mathbf{E}$} & \multirow[b]{2}{*}{ PPV } & \multirow[b]{2}{*}{ NPV } & \multirow[b]{2}{*}{ A } & \multicolumn{2}{|c|}{ Likelihood ratio } \\
\hline & & & & & & & Positive & Negative \\
\hline \multirow[t]{2}{*}{$<1.5$} & ERCP & $50 \%$ & $100 \%$ & $100 \%$ & $50 \%$ & $66.6 \%$ & - & 0.50 \\
\hline & EUS & $50 \%$ & $100 \%$ & $100 \%$ & $50 \%$ & $66.6 \%$ & - & 0.50 \\
\hline \multirow[t]{2}{*}{$\geq 1.5$} & ERCP & $60.9 \%$ & $100 \%$ & $100 \%$ & $5.3 \%$ & $61.9 \%$ & - & 0.39 \\
\hline & EUS & $95.7 \%$ & $100 \%$ & $100 \%$ & $33.3 \%$ & $95.8 \%$ & - & 0.04 \\
\hline
\end{tabular}

ERCP, endoscopic retrograde cholangiography; EUS, endoscopic ultrasound; S, sensitivity; E, specificity; PPV, predictive positive value; NPV, negative predictive value; A, accuracy

Traditionally, patients with indeterminate biliary strictures are evaluated and treated with ERCP. Biliary brushing is simple and safe, and given its high specificity, it is reliable when positive [9-11]. However, due to the low sensitivity rates, ranging from $30 \%$ to $91 \%$, a negative test result is not reliable $[10,11]$.

Another technique performed during ERCP is forceps biopsy, which is technically difficult and therefore used less often. It has the advantage of providing information about tissue structure and levels of invasion when performed with adequate depth. This information is not possible to gather with other methods [2]. After all, their sensitivity rates are also low, ranging from $30 \%$ to $88 \%[18,19]$. In our study, in the ITT analysis, the sensitivity and accuracy of the cytology brush and the biopsy were $39.6 \%$ and $42.0 \%$, and $43.8 \%$ and $46 \%$, respectively, with no statistical difference.

In duodenal papilla lesions, biopsy is the gold-standard method, with sensitivity varying from $77 \%$ to $88 \%$, and a specificity of $100 \%$ [20]. For this reason, such lesions were excluded from this protocol.

Tissue sampling with ERCP is very important, but due to its low sensitivity and the fact that in about $5 \%$ to $10 \%$ of cases, this method is not feasible to perform due to either technical difficulties or altered anatomy, as shown in our study in which we the failure rate was $12 \%$ when performing ERCP. For this reason, other procedures to obtain anatomopathological specimens are needed, such as EUS-FNA [2].

EUS can provide many additional information and help stage the lesion, which is a determining factor for tumor ressectability $[8,21,22]$.
EUS-FNA performs better in diagnosis of distal biliary strictures because distal lesions affecting the bile duct are usually located near the duodenal wall, where the EUS transducer is placed. Proximal strictures, in addition to the greater distance from the duodenal wall, tend to grow along the bile duct or to be diffusely infiltrative rather than to form solid masses, commonly seen in distal lesions, such as in pancreatic cancer [22]. Our study proved this statement, showing an accuracy of $97.1 \%$ in distal lesions and $86.7 \%$ in proximal lesions.

EUS-FNA's sensitivity in biliary strictures is heterogeneous, varying from $46 \%$ to $100 \%$ [5, $21-27]$, and specifically for intraductal lesions between $53 \%$ and $89 \%[6,23,24]$. Our study demonstrated good sensitivity for the method, with a sensitivity of $93.8 \%$ on the global analysis, $100 \%$ in extraductal lesions and $80 \%$ in intraductal lesions.

In general, EUS-FNA is a powerful diagnostic tool, and with its widespread use, we will depend less on ERCP for tissue sampling [9, 21].

In several studies, EUS-FNA was performed after a negative ERCP tissue sample result and showed excellent outcomes, suggesting that if the exams had been performed on the same day, during the same sedation, several patients would have benefited from early diagnosis $[5,6]$.

In the literature, there are 4 studies [24-27] similar to our study in which ERCP tissue sampling and EUS-FNA were performed on the same day. In 2 of these studies, [25,26] only ERCP-BB was performed and in the other 2 [24,27] as well as our study, ERCP-BB and ERCP-FB were performed. 
In a study similar to ours with 51 patients, Weilert et al., [27] reported failure of ERCP in 7 cases, which were also considered inconclusive. The sensitivity of EUS-FNA was $100 \%$ for pancreatic masses, and in the joint analysis of biliary strictures it was superior to ERCP, with sensitivity, specificity and accuracy of: $94 \%, 100 \%$ and $90 \%$, against $50 \%, 50 \%$ and $53 \%$, respectively, similar results to ours. Nonetheless, Weilert et al. performed EUS-FNA with presence of ROSE (rapid on site evaluation).

Unlike our study, in the report by Rösch et al. [24], no method was proven to be superior to another. With a combination of methods, as in our study, Rösch et al. did demonstrate increased accuracy.

Apparently, the association of methods could increase the number of complications, because a patient would undergo more than 1 procedure. Despite this, our study like others, demonstrated similar complication rates in comparison with studies in which both methods were not performed [24-27].

The use of 2 experienced pathologists contributed to our good results, because several studies have demonstrated an improvement in accuracy and sensitivity when evaluation is done by an experienced pathologist [25, 28].

Most anatomopathological reports divide evaluation of the specimens into 5 different categories: inadequate, benign, atypical, suspect or malignant [29].

Studies diverge on considering suspicious cases as malignant or benign at the time of calculations of efficiency [29]. This fact is related to the heterogeneity of the results published in the literature. Some authors report increased sensitivity in anatomopathological diagnosis, by adding diagnostic categories, such as suspect or atypical [28-31]. Other studies like ours do not include atypical or suspect cases [27,32] because a diagnosis based on doubtful criteria could result in unnecessary surgery $[26,33]$. In our study, IPMNs with solid masses greater than $2 \mathrm{~cm}$ and obstructing the biliary tract were considered malignant, since it is known that patients with these conditions present a prognosis similar to that of pancreatic adenocarcinoma, and that due to malignant potential, surgical resection is considered the treatment of choice [34].

EUS-FNA and ERCP tissue sampling have excellent specificity and positive predictive value in anatomopathological diagnosis of malignant biliary strictures, showing that a positive result for malignancy is very reliable. Despite the low negative predictive value, demonstrating a negative result, malignant disease cannot be excluded.

Although EUS has not traditionally been considered as useful as ERCP in evaluating primary biliary strictures $[6,9,21]$, this study demonstrates that EUS-FNA is superior to ERCP in diagnosis of malignant biliary stricture. In clinical practice, as in this investigation, most cases that cause strictures or obstruction of the biliary tract are caused by pancreatic cancer, which may explain the low sensitivity of ERCP-BB and ERCP-FB, since it is not surprising that rates of detection of malignant neoplasm by ERCP are higher for lesions originating from the bile epithelium $[2,9]$. The other method indicated for these lesions is cholangioscopy, which provides direct visualization of strictures and allows for targeted biopsies and may help diagnose or rule out malignancy in indeterminate strictures, especially CCA. In a recent systematic review and meta-analysis, including 10 studies, the pooled sensitivity and specificity for diagnosis of cholangioscopy-guided biopsies in diagnosis of malignant biliary strictures were $60.1 \%$ and $98.0 \%$, respectively. Specifically for CCA diagnosis, the pooled sensitivity and specificity were $66.2 \%$ and $97.0 \%$, respectively [35].

The fact that this study presents more extraductal and distal lesions may be considered a limitation since they may have favored the superior results of the EUS. Given the fourfold incidence of pancreatic neoplasm in comparison to primary biliary tract tumors [36], however, almost twice as many were identified in our study, and the good results obtained with EUS-FNA in cholangiocarcinoma lead us to believe that if only 1 method is to be performed, EUS should be done before ERCP in patients with indeterminate biliary stricture, regardless of the type of suspicious tumor.

With the combination of EUS and ERCP, our study obtained a sensitivity of $97.9 \%$, specificity of $100 \%$ and accuracy of $98 \%$, suggesting an extremely high chance of obtaining a concrete diagnosis using both methods. For this reason, in the case of suspected malignant biliary stricture, we suggest performing the 2 methods.

\section{Conclusion}

EUS-FNA is better than ERCP with brush cytology and intraductal forceps biopsy in diagnosing malignant biliary strictures, mainly in assessment of extraductal lesions and those larger than $1.5 \mathrm{~cm}$. Combining ERCP with tissue sampling and EUSFNA is feasible, the techniques have similar complication rates, and the combination greatly improves diagnostic accuracy.

\section{Competing interests}

\section{None}

References

[1] De Moura DT, Moura EG, Bernardo WM etal. Endoscopic retrograde cholangiopancreatography versus endoscopic ultrasound for tissue diagnosis of malignant biliary stricture: Systematic review and metaanalysis. Endosc Ultrasound 2016: doi:10.4103/2303-9027.193597 [Epub ahead of print]

[2] Navaneethan U, Njei B, Lourdusamy V et al. Comparative effectiveness of biliary brush cytology and intraductal biopsy for detection of malignant biliary strictures: a systematic review and meta-analysis. Gastrointest Endosc 2015; 81: 168-176

[3] Yoon W], Brugge WR. Endoscopic evaluation of bile duct strictures. Gastrointest Endosc Clin N Am 2013; 23: 277 - 293

[4] American Society for Gastrointestinal Endoscopy (ASGE) Standards of Practice Committee, Anderson MA, Appalaneni V, Ben-Menachem T et al. The role of endoscopy in the evaluation and treatment of patients with biliary neoplasia. Gastrointest Endosc 2013; 77: 167-174

[5] DeWitt J, Misra VL, Leblanc JK et al. EUS-guided FNA of proximal biliary strictures after negative ERCP brush cytology results. Gastrointest Endosc 2006; 64: 325-333 
[6] Fritscher-Ravens A, Broering DC, Knoefel WT et al. EUS-guided fineneedle aspiration of suspected hilar cholangiocarcinoma in potentially operable patients with negative brush cytology. Am J Gastroenterol 2004; 99: 45 - 51

[7] Cui XW, Ignee A, Braden B et al. Biliary papillomatosis and new ultrasound imaging modalities. Z Gastroenterol 2012; 50: 226-231

[8] Fusaroli P, Napoleon B, Gincul R et al. The clinical impact of ultrasound contrast agents in EUS: a systematic review according to the levels of evidence. Gastrointest Endosc 2016; 84: 587-596

[9] Korc P, Sherman S. ERCP tissue sampling. Gastrointest Endosc 2016; 84: $557-571$

[10] Ponchon T, Gagnon F, Berger F. Value of endobiliary brush cytology and biopsies for the diagnosis of malignant bile duct stenosis: results of a prospective study. Gastrointest Endosc 1995; 42: 565- 572

[11] Burnett AS, Calvert T], Chokshi RJ. Sensitivity of endoscopic retrograde cholangiopancreatography standard cytology: 10-y review of the literature. J Surg Res 2013; 184: 304-311

[12] Nanda A, Brown JM, Berger SH et al. Triple modality testing by endoscopic retrograde cholangiopancreatography for the diagnosis of cholangiocarcinoma. Therap Adv Gastroenterol 2015; 8: 56-65

[13] Bosman FT, Carneiro F, Hruban RH et al. WHO classification of tumors of the digestive system. Vol. 3. 4. ed. WHO/IARC classification of tumors; 2010

[14] Pocock S]. Clinical Trials: A Practilcal Approach. Wiley; 1983. Sealed Envelope Ltd. Power calculator for binary outcome superiority trial. [Online] Avaiable from: https://www.sealedenvelope.com/power/binary-superiority/

[15] Catmaker. Available at: http://www.cebm.net/catmaker-ebm-calculators/

[16] Busnello Ellis D’A, Tannous L, Gigante L et al. Confiabilidade diagnóstica dos transtornos mentais da versão para cuidados primários da Classificação Internacional das Doenças. Rev. Saúde Pública 1999; 33 : 487 - 494 [cited 2017 Jan 30]

[17] Freeman ML, Nelson DB, Sherman S et al. Complications of endoscopic biliary sphincterotomy. N Engl J Med 1996; 335: 909-918

[18] De Bellis M, Sherman S, Fogel EL et al. Tissue sampling at ERCP in suspected malignant biliary strictures (Part 1). Gastrointest. Endosc 2002; 56: $552-561$

[19] De Bellis M, Sherman S, Fogel EL et al. Tissue sampling at ERCP in suspected malignant biliary strictures (Part 2). Gastrointest. Endosc 2002; 56: $720-730$

[20] Menzel ], Poremba C, Dietl KH et al. Tumors of the papilla of Vaterinadequate diagnostic impact of endoscopic forceps biopsies taken prior to and following sphincterotomy. Ann Oncol 1999; 10: 1227 1231

[21] Onda S, Ogura T, Kurisu Y et al. EUS-guided FNA for biliary disease as first-line modality to obtain histological evidence. Therap Adv Gastroenterol 2016; 9: 302-312
[22] Mohamadnejad M, DeWitt JM, Sherman S et al. Role of EUS for preoperative evaluation of cholangiocarcinoma: a large single-center experience. Gastrointest Endosc 2011; 73: 71- 78

[23] Eloubeidi MA, Chen VK, Jhala NC et al. Endoscopic ultrasound-guided fine needle aspiration biopsy of suspected cholangiocarcinoma. Clin Gastroenterol Hepatol 2004; 2: 209-213

[24] Rösch T, Hofrichter K, Frimberger E et al. ERCP or EUS for tissue diagnosis of biliary strictures? A prospective comparative study Gastrointest Endosc 2004; 60: 390 - 396

[25] Novis M, Ardengh JC, Libera ED et al. Prospective comparative study of ERCP brush cytology and EUS-FNA for the differential diagnosis of biliary strictures. Rev Col Bras Cir 2010; 37: 190 - 198

[26] Oppong K, Raine D, Nayar M et al. EUS-FNA versus biliary brushings and assessment of simultaneous performance in jaundiced patients with suspected malignant obstruction. JOP 2010; 11: 560 - 567

[27] Weilert F, Bhat YM, Binmoeller KF et al. EUS-FNA is superior to ERCPbased tissue sampling in suspected malignant biliary obstruction: results of a prospective, single-blind, comparative study. Gastrointest Endosc 2014; 80: 97 - 104

[28] Wight CO, Zaitoun AM, Boulton-Jones JR et al. Improving diagnostic yield of biliary brushings cytology for pancreatic cancer and cholangiocarcinoma. Cytopathology 2004; 15: 87-92

[29] Naitoh I, Nakazawa T, Kato A et al. Predictive factors for positive diagnosis of malignant biliary strictures by transpapillary brush cytology and forceps biopsy. J Dig Dis 2016; 17: 44-51

[30] Lee JG, Leung JW, Baillie J et al. Benign, dysplastic, or malignantmaking sense of endoscopic bile duct brush cytology: results in 149 consecutive patients. Am J Gastroenterol 1995; 90: 722 - 726

[31] Logroño R, Wong JY. Reporting the presence of significant epithelial atypia in pancreaticobiliary brush cytology specimens lacking evidence of obvious carcinoma: impact on performance measures. Acta Cytol 2004; 48: 613-621

[32] Moreno-Luna LE, Kipp B, Halling KC. Advanced cytologic techniques for the detection of malignant pancreatobiliary strictures. Gastroenterology 2006; 131: $1064-1072$

[33] Levy M], Baron TH, Calyton AC. Prospective evaluation of advanced molecular markers and imaging techniques in patients with indeterminate bile duct strictures. Am J Gastroenterol 2008; 103: 1263 1273

[34] Tanaka M, Chari S, Adsay V et al. International consensus guidelines for management of intraductal papillary mucinous neoplasms and mucinous cystic neoplasms of the pancreas. Pancreatology 2006; 6: $17-32$

[35] Navaneethan U, Hasan MK, Lourdusamy V et al. Single-operator cholangioscopy and targeted biopsies in the diagnosis of indeterminate biliary strictures: a systematic review. Gastrointest Endosc 10 2015; 82: $608-614$

[36] American Cancer Society. Cancer Facts \& Figures 2013. Atlanta (Ga): American Cancer Society; 2013 